\title{
Change of Subcutaneous Tissue Mass at the Deltoid and Thigh Areas in Japanese Infants Followed from 2 to 15 Months
}

\author{
Tetsuo Nakayama ${ }^{1 *}$, Toshihiro Tanaka ${ }^{2}$, Motoko Fujino ${ }^{3}$, Minoru Kino ${ }^{4}$, Yuka Kunitomi5, \\ Keitaro Yatabe $^{5}$
}

\author{
${ }^{1}$ Kitasato Institute for Life Sciences, Laboratory of Viral Infection II, Tokyo, Japan \\ ${ }^{2}$ Department of Pediatrics, Shizuoka Kosei Hospital, Shizuoka, Japan \\ ${ }^{3}$ Department of Pediatrics, Saiseikai Central Hospital, Tokyo, Japan \\ ${ }^{4}$ Department of Pediatrics, Nakano Children's Hospital, Osaka, Japan \\ ${ }^{5}$ Department of Clinical Development \& Medical Affairs, Japan Vaccine Co., Ltd., Tokyo, Japan \\ Email: ${ }^{\star}$ tetsuo-n@lisci.kitasato-u.ac.jp
}

How to cite this paper: Nakayama, T., Tanaka, T., Fujino, M., Kino, M., Kunitomi, Y. and Yatabe, K. (2018) Change of Subcutaneous Tissue Mass at the Deltoid and Thigh Areas in Japanese Infants Followed from 2 to 15 Months. Open Journal of Pediatrics, 8, 324-333.

https://doi.org/10.4236/ojped.2018.84033

Received: October 4, 2018

Accepted: December 1, 2018

Published: December 4, 2018

Copyright $\odot 2018$ by authors and Scientific Research Publishing Inc. This work is licensed under the Creative Commons Attribution International License (CC BY 4.0)

http://creativecommons.org/licenses/by/4.0/

(c) (i) Open Access

\begin{abstract}
We previously investigated the thickness of the epidermis and lengths from the skin surface to the muscle fascia and bone based on measurements taken from the ultrasonic echograms of Japanese infants aged 2, 3, 4, 5, 6, and 12 15 months. The appropriate needle length for intramuscular injection was 16 $\mathrm{mm}(5 / 8 \mathrm{inch})$ in Japanese infants at any age and site. In the present study, we examined these lengths in 21 infants with physical growth from 2 to 15 months. Average height increased from 58.5 to $73.6 \mathrm{~cm}$ and average body weight from 5835 to $9226 \mathrm{~g}$ until 15 months. The circumference of the thigh increased from $22.3 \mathrm{~cm}$ at 2 months to a maximum of $25.9 \mathrm{~cm}$ at 6 months, while that of the deltoid area was $15.2 \mathrm{~cm}$ at 2 months and $15.9 \mathrm{~cm}$ at 6 months. Subcutaneous mass (length from the skin surface to the muscle fascia) at the thigh increased between 3 and 4 months and decreased at $12-15$ months and showed good relationship to the circumference of the thigh. Subcutaneous mass at the center of the deltoid area showed the same size until 6 months. Muscle mass (lengths from the muscle fascia to the bone) at thigh and deltoid areas remained the same until 6 months. Ultrasonic echogram is an effective tool for evaluating subcutaneous and muscle mass in young infants.
\end{abstract}

\section{Keywords}

Intramuscular Injection, Subcutaneous Mass, Muscle Mass, Vaccines 


\section{Introduction}

Alum-adjuvanted vaccines have been used since the introduction of diphtheria and tetanus toxoids combined with the acellular pertussis vaccine (DTaP) in 1981. Pneumococcal (PCV13) and hepatitis B virus (HBV) vaccines were introduced into recommended immunization in 2010 and 2016, respectively. These alum-adjuvanted vaccines are administered from two months of age [1]. They are administered intramuscularly (IM) in most countries, but subcutaneously (SC) in Japan. Muscle contracture was reported in the 1960s caused by multiple IM injections of antibiotics and antipyretics. There was no case caused by vaccine administration, but IM procedure has been prohibited. Serious local pain has been reported through SC administration, and among them some recipients exhibited local induration for several weeks [2]. All adjuvanted vaccines are administered IM worldwide without serious local reactions [3].

Immunization schedule starts at 2 months of age, and most vaccines are administered SC at the middle of the lateral thigh or center of the deltoid area. In order to promote IM procedure, anatomical lengths from the skin surface to the muscle fascia and bone were previously evaluated in a clinical study to assess appropriate lengths for infants by ultrasonic echography on 30 volunteer infants aged 2, 3, 4, 5, 6, and 12 - 15 months [4]. The appropriate needle length for IM administration was found to be $16 \mathrm{~mm}$ at any age (month) and site. That study was a cross-sectional analysis.

We supposed that the different local reactions depend on the subcutaneous and muscle mass. The object of the present study is to investigate the relationship between the mass and physical growth of infants, height, body weight, body mass index (BMI), and circumference, as they grow from 2 to 15 months by ultrasonic echography.

\section{Materials and Methods}

\subsection{Study Design}

In order to assess the physical growth, 21 healthy Japanese infants (12 male and 9 female infants) were enrolled from those who visited the Department of Pediatrics of two general hospitals between August 2015 and October 2016 at Saiseikai Central Hospital, Tokyo and Shizuoka Kosei Hospital, Shizuoka. Twenty-one infants were initially enrolled at 2 months of age and were followed until 15 months. Some data were excluded from the final analysis because of unclear ultrasonic echography images. Therefore, 18 images at 3 and 4 months, 16 at 5 and 6 months, and 18 at 12 - 15 months were analyzed. The target months of age were selected according to the recommended immunization schedule for infants by the Japan Pediatric Society [1]. Body weight, height, and the circumferences of the upper arm at the center of the deltoid muscle and middle position of the thigh were measured. Inclusion and exclusion criteria were as follows:

Inclusion criteria

1) Written consent was obtained from infants' families. 
2) Infants who had grown healthily after birth without any chronic ailments. Even if infants had some chronic illness (such as febrile convulsion, cardiac anomaly without heart failure), they were included when medical investigators judged it to have no influence on the measurements being taken.

Exclusion criteria

1) Infants with an abnormality in their extremities.

2) Infants with serious chronic ailments related to developmental disorders or neurological or muscular diseases.

3) Infants not cooperative with measurements.

4) Infants' families (guardians or legally acceptable representatives) for whom written consent was not obtained.

The thickness of the epidermis and lengths from the surface of the skin to the muscle fascia and bone were measured using ultrasonic echograms. The objectives and design of the present study were explained to infants' families (guardians or legally acceptable representatives), and written informed consent was obtained. This study protocol was reviewed and approved by the Ethics Committees of Saiseikai Central Hospital, and Shizuoka Kosei Hospital. This study was conducted in accordance with Ethical Guidelines for Medical and Health Research Involving Human Subjects (Dec. 2014, The Ministry of Education, Culture, Sports, Science and Technology; Ministry of Health, Labour and Welfare) and Ethical Principles based on the Declaration of Helsinki.

\subsection{Ultrasonic Echography}

Ultrasonic echography was performed on the middle of the deltoid muscle and middle of the lateral thigh using Aplio 400/500 with the linear probe PLT-704SBT (Toshiba Medical Systems, Japan), and Prosound SSD- $\alpha 10$ with the linear probe UST-5411 (Hitachi Aloka-Medical, Japan). The thickness of the epidermis and lengths from the skin surface to the muscle fascia and bone were measured based on the different intensities of echograms while stretching the skin flat [4]. Ultrasonic images were examined by a medical echogram specialist and unclear blurred images were excluded from the analysis. A typical ultrasonic image at the deltoid area is shown in Figure 1.

\subsection{Statistical Analyses}

Statistical significance was determined by Welch's $t$ test. Statistical analyses were performed using SAS ver. 9.2 software.

\section{Results}

\subsection{Physical Growth and Circumferences at Injected Sites}

The physical growth of height and body weight was measured and the results obtained are shown in Figure 2. The background of participants was $37-42$ gestational weeks without abnormalities during pregnancy and delivery. The heights of $81 \%$ of participants ranged between 55 and $60 \mathrm{~cm}$, while the body 
weights of $57 \%$ were $5000-6000 \mathrm{~g}$ at 2 months. They grew normally until $12-15$ months in accordance with the normal growth curves of Japanese children. These results were within cross sectional average of body weight and height of 95\% of Japanese infants. Mean body mass index (BMI) was $17-17.8$ without any significant changes.

The circumferences of the middle of the lateral thigh, center of the deltoid muscle area, and the lower $1 / 3$ of the upper arm were measured and the results obtained are shown in Figure 3. The circumference of the thigh was $22.3 \pm 1.72 \mathrm{~cm}$ at 2 months and increased to a maximum of $25.92 \pm 2.06 \mathrm{~cm}$ at 6 months. The circumference of the center of the deltoid muscle area was $15.18 \pm 1.45 \mathrm{~cm}$ at 2 months and increased to a maximum of $17.46 \pm 1.57 \mathrm{~cm}$ at 6 months. The circumference of the lower $1 / 3$ of the upper arm was $14.18 \pm 1.54 \mathrm{~cm}$ at 2 months and $15.89 \pm 1.10 \mathrm{~cm}$ at 6 months.

\subsection{Lengths from the Surface of the Skin to the Muscle Fascia and Bone at the Thigh}

The thickness of the epidermis and lengths from the skin surface to muscle fascia and bone were identified by different ultrasonic intensities and results are shown as means $\pm 1.0 \mathrm{SD}$ in Figure 4(a). The mean thickness of the epidermis was $1.78 \pm 0.39 \mathrm{~mm}$ at 2 months and $1.82 \pm 0.48 \mathrm{~mm}$ at $12-15$ months. The length from the skin surface to the muscle fascia was $10.30 \pm 2.21 \mathrm{~mm}$ at 2

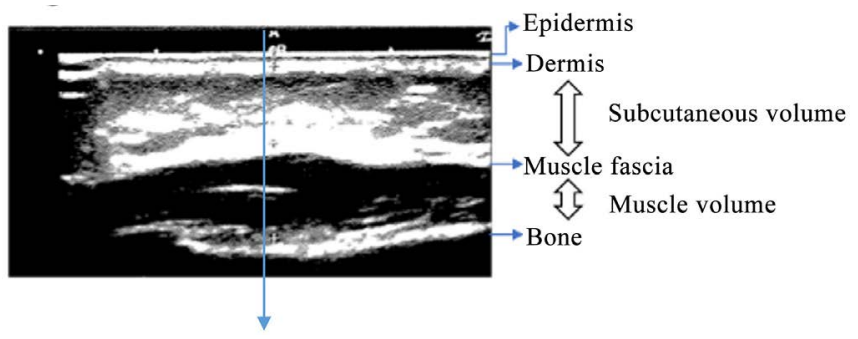

Figure 1. Typical ultrasonic image of deltoid area. Ultrasonic image obtained from the subject 5 months of age at the deltoid area is shown. Thickness of epidermis and length were measured based on the different intensity of echogram along with the blue line.
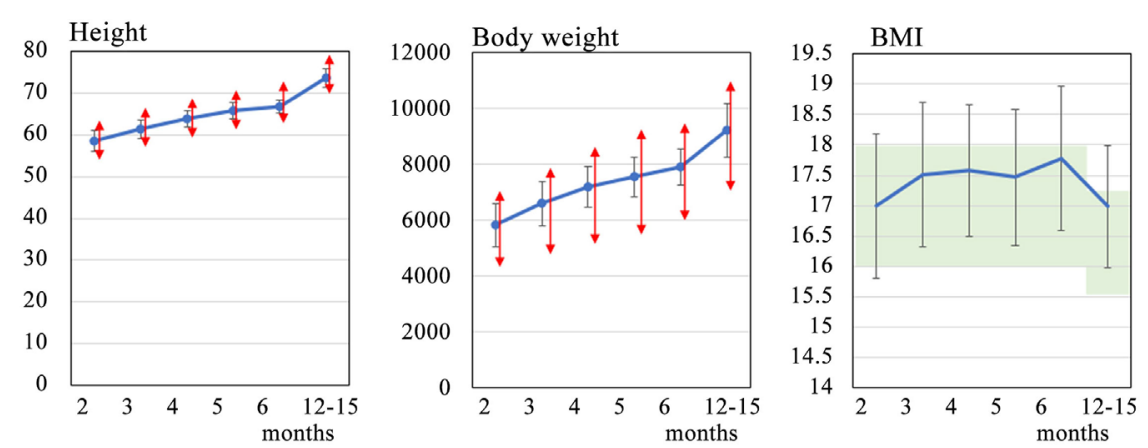

Figure 2. Changes in height, body weight, and BMI with physical growth. Height, body weight, and BMI were measured and shown as the mean \pm 1.0 SD. Red arrows show the cross-sectional average of body weight and height of the $95 \%$ of Japanese infants. Green zone shows appropriate BMI. 


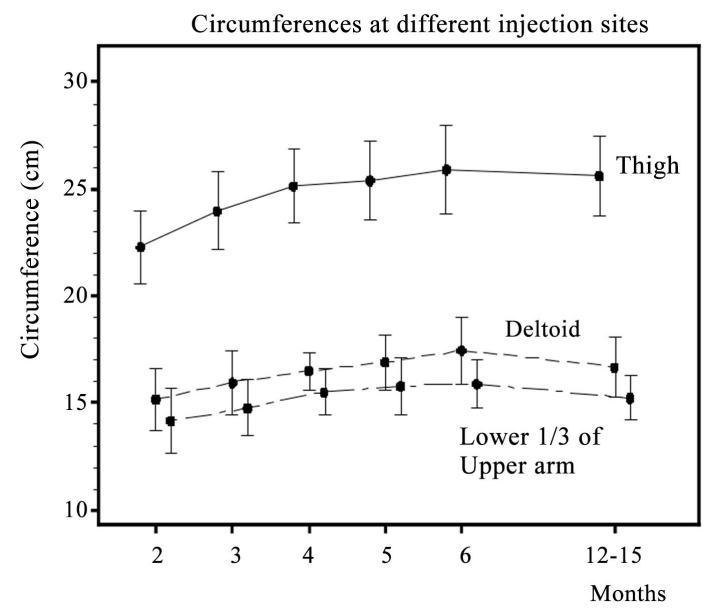

Figure 3. Circumferences of the thigh, upper arm at the deltoid muscle, and lower $1 / 3$ of the upper arm in different age groups (months). Circumferences are shown as the mean \pm SD $(\mathrm{cm})$.

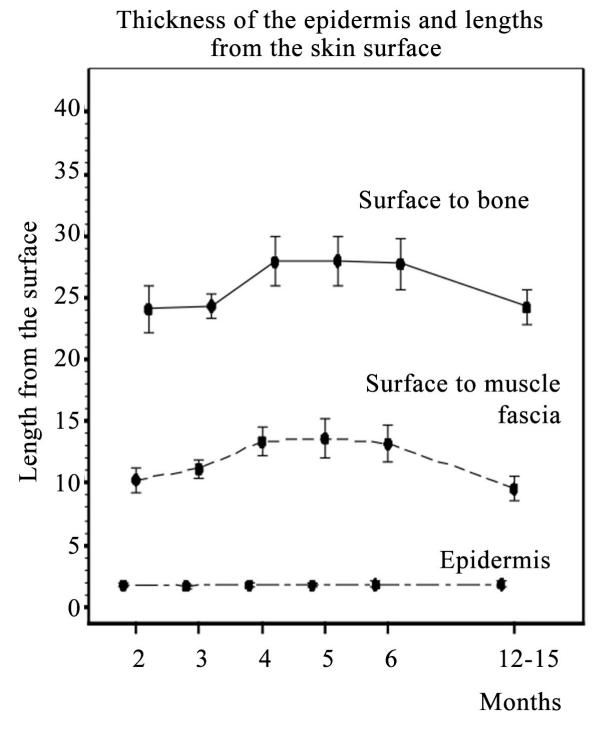

(a)

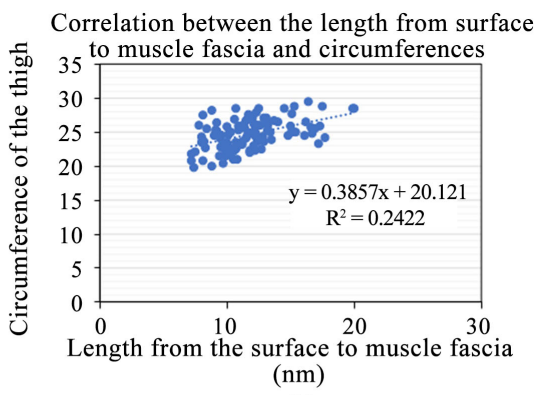

(b)

Correlation between the length from the

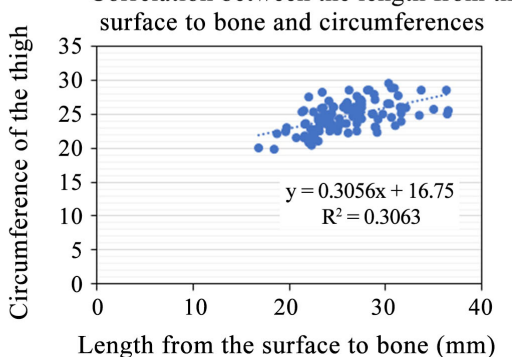

(c)

Figure 4. Thickness of the epidermis, lengths from the skin surface to the muscle fascia and bone at the thigh, and the relationship between length and circumference. (a) Thickness of the epidermis and lengths are shown as the mean $\pm 1.0 \mathrm{SD}(\mathrm{mm})$. (b) Relationship between circumference and length from the skin surface to muscle fascia. (c) Relationship between circumference and length from the skin surface to the bone.

months, maximum length was $13.62 \pm 2.83 \mathrm{~mm}$ at 5 months, and this decreased to $9.59 \pm 2.05 \mathrm{~mm}$ at $12-15$ months. The length from the skin surface to bone was $24.08 \pm 4.33 \mathrm{~mm}$ at 2 months, maximum length was $28.02 \pm 3.74 \mathrm{~mm}$ at 5 months, and this decreased to $24.25 \pm 2.74 \mathrm{~mm}$ at $12-15$ months. It increased for 3 - 4 months, remained similar length at $4-6$ months, and then decreased at 12 - 15 months.

We investigated a correlation coefficient ( $r$ ) between body size and length 
from the skin surface to the muscle fascia and bone. The circumference around the middle thigh area was more closely related to the length from the skin surface to bone $(r=0.55)$ than that to the muscle fascia $(r=0.49)$ (Figure $4(b)$ and Figure 4(c)).

No relationship was noted between the length from the skin surface to bone and body weight or height, but weak relationship was observed between that to BMI $(r=0.48)$ (Figure 5(a), Figure 5(b), and Figure 5(c)).

\subsection{Lengths from the Surface of the Skin to the Muscle Fascia and Bone at the Deltoid Muscle}

The thicknesses of the epidermis and the length from the skin surface to muscle fascia and bone were examined at the deltoid muscle, and the results obtained are shown in Figure 6. The mean thickness of the epidermis was $1.86 \pm 0.44 \mathrm{~mm}$ at 2 months and $1.93 \pm 0.64 \mathrm{~mm}$ at 6 months. The length from the skin surface to the muscle fascia was $9.13 \pm 2.15 \mathrm{~mm}$ at 2 months, maximum length was 9.51 $\pm 1.98 \mathrm{~mm}$ at 4 months, and decreased to $6.36 \pm 1.19 \mathrm{~mm}$ at $12-15$ months. The length from the skin surface to the bone was $17.83 \pm 2.44 \mathrm{~mm}$ at 2 months, maximum length was $19.55 \pm 3.14 \mathrm{~mm}$ at 5 months, and decreased to $17.04 \pm$ $2.16 \mathrm{~mm}$ at $12-15$ months. No relationship was observed between the circumference at the middle of the deltoid area and the length from the skin surface to the muscle fascia or to bone.

\subsection{Subcutaneous Tissue Mass and Muscle Volume}

The difference in length between the thickness of the epidermis and that from the skin surface to the muscle fascia reflects the subcutaneous tissue mass. Muscle volume is defined as the difference between the length from the skin surface to bone and that to the muscle fascia. The results obtained are shown in Table 1. The subcutaneous tissue mass at the middle of the thigh increased significantly between 3 and 4 months $(\mathrm{p}=0.006)$ and significantly decreased at $12-15$ months in comparison with that at 6 months $(\mathrm{p}<0.001)$. The subcutaneous tissue mass at the center of the deltoid area was the same until 6 months and decreased at $12-15$ months. No significant increases in muscle volumes at the thigh and deltoid areas were observed as they grew up until 12 - 15 months.

\section{Discussion}

Two IM injection techniques are employed by bunching the thigh muscle at the injection site and stretching the skin surface, and the site recommended is the thigh for infants $<12$ months and the deltoid muscle area for those $>1$ year [5] [6]. The incidence of local pain at injection sites varies not only for needle lengths, but also for the age of immunization. A relationship has been reported between the incidence of local reactions and a needle length of 16 or $25 \mathrm{~mm}$, and fewer local adverse reactions were noted in those immunized using the $25-\mathrm{mm}$ needle with similar immune responses [7]. The incidence of local redness and pain due to intramuscular injection into the thigh is higher in infants aged 18 
months, probably because they start walking at around this age [8]. We investigated the local reactions following immunization with alum-adjuvanted vaccines in experimental mouse level. They induced inflammatory nodules following injection through IM and SC with local production of inflammatory cytokine but non-adjuvanted vaccines didn't. Inflammatory nodules were absorbed earlier in the case of IM than in that of SC injection [9]. We suppose that the local pain is related to the inflammatory nodule in subcutaneous or muscular mass. Subcutaneous tissue consists of connective tissue and fat. Nerve cells (nociceptors) are

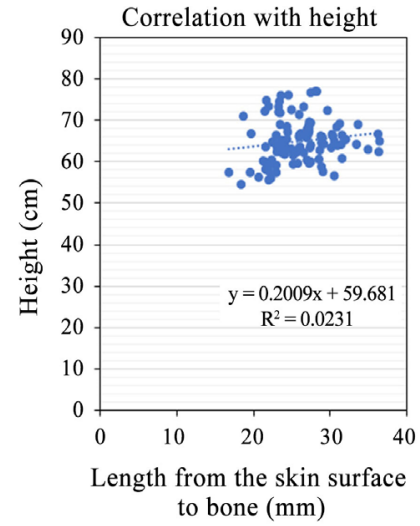

(a)

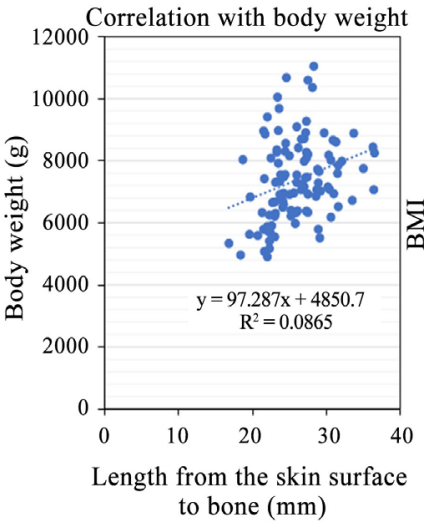

(b)

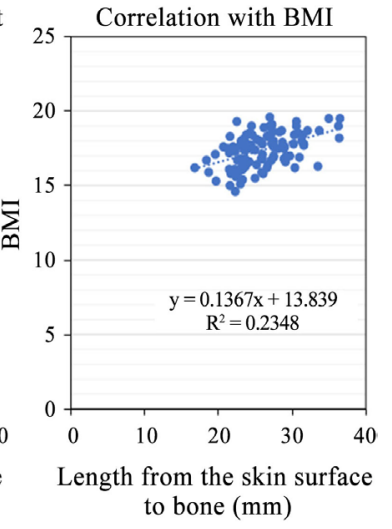

(c)

Figure 5. Relationships between length from the skin surface to bone and height, body weight, and BMI.

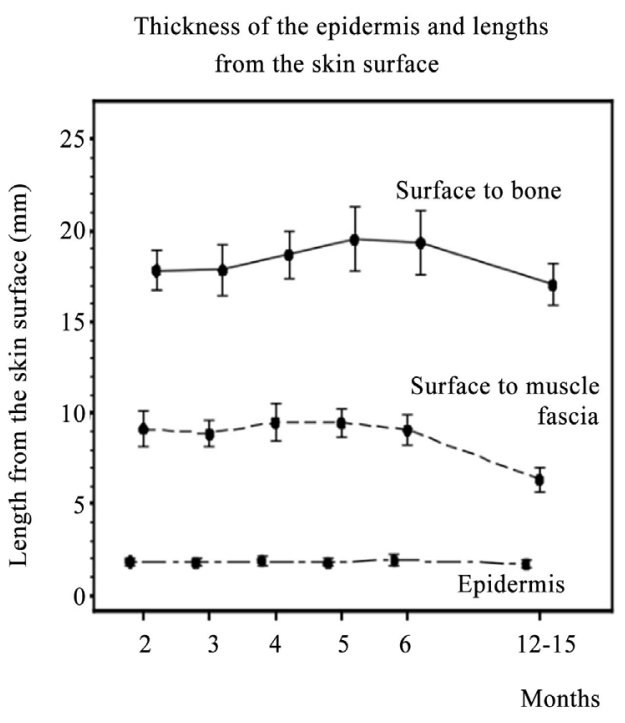

(a)

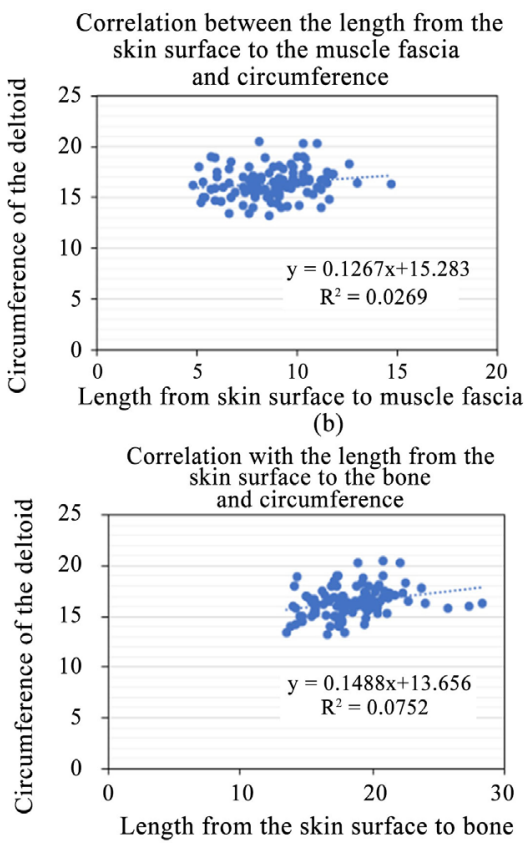

(c)

Figure 6. Thickness of the epidermis and lengths from the skin surface to the muscle fascia and bone at the middle of the deltoid muscle area. (a) Thickness of the epidermis and lengths are shown as the mean $\pm 1.0 \mathrm{SD}$ (mm). (b) Relationship between circumference and length from the skin surface to muscle fascia. (c) Relationship between circumference and length from the skin surface to the bone. 
Table 1. Subcutaneous and muscle volumes at the thigh and deltoid area between 2 and 15 months.

\begin{tabular}{|c|c|c|c|c|c|c|}
\hline & Thigh & Subcutaneous & Muscle & Deltoid & Subcutaneous & Muscle \\
\hline $2 \mathrm{M}$ & $\mathrm{n}=21$ & $\begin{array}{c}8.52 \\
{[7.53-9.51]}\end{array}$ & $\begin{array}{c}13.79 \\
{[12.34-15.23]}\end{array}$ & $\mathrm{n}=21$ & $\begin{array}{c}7.28 \\
{[6.337-8.19]}\end{array}$ & $\begin{array}{c}8.70 \\
{[7.94-9.45]}\end{array}$ \\
\hline $3 \mathrm{M}$ & $\mathrm{n}=18$ & $\begin{array}{c}9.51^{\star} \\
{[8.66-10.35]}\end{array}$ & $\begin{array}{c}13.16 \\
{[12.20-14.12]}\end{array}$ & $\mathrm{n}=18$ & $\begin{array}{c}7.07 \\
{[6.41-7.72]}\end{array}$ & $\begin{array}{c}8.98 \\
{[7.72-10.24]}\end{array}$ \\
\hline $4 \mathrm{M}$ & $\mathrm{n}=18$ & $\begin{array}{c}11.62^{*} \\
{[10.34-12.90]}\end{array}$ & $\begin{array}{c}14.57 \\
{[13.22-15.91]}\end{array}$ & $\mathrm{n}=17$ & $\begin{array}{c}7.61 \\
{[6.75-8.47]}\end{array}$ & $\begin{array}{c}9.17 \\
{[8.47-9.87]}\end{array}$ \\
\hline $5 \mathrm{M}$ & $\mathrm{n}=16$ & $\begin{array}{c}11.84 \\
{[10.33-13.35]}\end{array}$ & $\begin{array}{c}14.40 \\
{[13.12-15.68]}\end{array}$ & $\mathrm{n}=15$ & $\begin{array}{c}7.67 \\
{[6.81-8.53]}\end{array}$ & $\begin{array}{c}10.08 \\
{[8.18-11.98]}\end{array}$ \\
\hline $6 \mathrm{M}$ & $\mathrm{n}=16$ & $\begin{array}{c}11.41^{*} \\
{[9.82-12.99]}\end{array}$ & $\begin{array}{c}14.56 \\
{[13.63-15.48]}\end{array}$ & $\mathrm{n}=15$ & $\begin{array}{c}7.15^{*} \\
{[6.45-7.86]}\end{array}$ & $\begin{array}{c}10.27 \\
{[9.00-11.55]}\end{array}$ \\
\hline $12-15 \mathrm{M}$ & $\mathrm{n}=18$ & $\begin{array}{c}7.77^{*} \\
{[6.82-8.73]}\end{array}$ & $\begin{array}{c}14.65 \\
{[13.59-15.72]}\end{array}$ & $n=16$ & $\begin{array}{c}4.64^{*} \\
{[3.97-5.32]}\end{array}$ & $\begin{array}{c}10.68 \\
{[9.68-11.68}\end{array}$ \\
\hline
\end{tabular}

*Significant difference was observed in the subcutaneous mass at thigh between 3 and 4 months and between 6 and $12-15$ months, and subcutaneous mass at deltoid between 6 and $12-15$ months $(\mathrm{p}<0.01)$.

abundant in the hypodermis subcutaneous mass than in the muscle tissue. Increasing volume of subcutaneous mass after $3-4$ months is related to the local reactions following SC injection.

In the present study, 21 infants were followed from 2 to 12 - 15 months. Muscle volumes at the thigh and deltoid areas appeared to remain similar from 2 to 12 - 15 months and no significant change was observed in the thickness of the epidermis. Ultrasonic echo-image from muscle fascia to bone at thigh represents the muscle volume of quadriceps. Recently, muscle volume calculated by three-dimensional ultrasound imaging method at medial gastrocnemius muscle was used to take early interventions for patients with cerebral palsy (CP) [10] [11] [12]. Medial gastrocnemius muscle increased the same rate in normal infants and patients with CP until 12 months. But muscle growth was reduced before development of the spasticity of the patients with $\mathrm{CP}$.

The subcutaneous tissue mass at the thigh increased between 3 and 4 months, remained the same until 6 months, and then decreased at $12-15$ months. At this age ( 4 - 6 months), it would be consistent with the timing when the subcutaneous soft tissue enlarges in the plump thighs, but not in the deltoids. Subcutaneous fat mass was measured as skinfold thickness using a caliper and total subcutaneous fat mass was calculated from the sum of skinfold thickness at biceps, triceps, suprailiacal, and subscapular sites. This calculation was used to investigate the influence of maternal obesity, gestational diabetes mellitus, maternal smoking, and infant diet on infant obesity [13] [14] [15].

The present method was a preliminary investigation only for limited number of healthy infants and should be applied for the patients with CP or above conditions. 


\section{Conclusion}

Ultrasonic echo-imaging at the thigh and deltoid areas is a simple method to determine the subcutaneous tissue and muscle volume measuring the length from the skin surface to the muscle fascia and bone. The subcutaneous tissue mass at the thigh area increased from 3 to 4 months until 6 months and decreased at 12 15 months. No significant increases in muscle volumes at the thigh and deltoid area were observed.

\section{COI}

Tetsuo Nakayama and Minoru Kino receive research funds of Japan Vaccine Co. Ltd. KeitaroYatabe and Yuka Kunitomi are employees of Japan Vaccine Co. Ltd.

\section{Acknowledgements}

The authors thank the doctors, nurses, radiological technicians, parents, and children involved in the conduct of this study. We would also like to thank Yukikazu Hayashi and Ryo Watanabe in A2 Healthcare Corporation for their assistance with statistical analyses. The study sponsor was Japan Vaccine Co., Ltd.

\section{Conflicts of Interest}

The authors declare no conflicts of interest regarding the publication of this paper.

\section{References}

[1] Nakayama, T. (2013) Vaccine Chronicle in Japan. Journal of Infection and Chemotherapy, 19, 787-798. https://doi.org/10.1007/s10156-013-0641-6

[2] Larson, H., Wilson, R., Hanley, S., Parys, A. and Paterson, P. (2014) Tracking the Global Spread of Vaccine Sentiments: The Global Response to Japan's Suspension of Its HPV Vaccine Recommendation. Human Vaccines \& Immunotherapeutics, 10, 2543-2550. https://doi.org/10.4161/21645515.2014.969618

[3] Herzog, C. (2014) Influence of Parenteral Administration Routes and Additional Factors on Vaccine Safety and Immunogenicity: A Review of Recent Literature. $E_{X}$ pert Reviews of Vaccines, 13, 399-415. https://doi.org/10.1586/14760584.2014.883285

[4] Nakayama, T., Kohdera, U., Fujino, M., Tanaka, T., Yatabe, K., Hashiguchi, T., Sato, T. and Kino, M. (2016) Appropriate Needle Lengths Determined Using Ultrasonic Echograms for Intramuscular Injections in Japanese Infants. Open Journal of Pediatrics, 6, 163-170. https://doi.org/10.4236/ojped.2016.62024

[5] Centers for Disease Control and Prevention (2011) General Recommendations on Immunization: Recommendations of the Advisory Committee on Immunization Practices (ACIP). $M M W R, 260,1-60$.

[6] World Health Organisation (2015) Immunisation in Practice. A Practical Resource Guide for Healthcare Workers. Geneva.

[7] Diggle, L., Deeks, J.J. and Pollard, A.J. (2006) Effect of Needle Size on Immunogenicity and Reactogenicity of Vaccines in Infants: Randomised Controlled Trial. British Medical Journal, 333, 571. https://doi.org/10.1136/bmj.38906.704549.7C 
[8] Ipp, M.M., Gold, R., Goldbach, M., Maresky, D.C., Saunders, N., Greenberg, S. and Davy, T. (1989) Adverse Reactions to Diphtheria, Tetanus, Pertussis-Polio Vaccination at 18 Months of Age: Effect of Injection Site and Needle Length. Pediatrics, 83, 679-682.

[9] Kashiwagi, Y., Maeda, M., Kawashima, H. and Nakayama, T. (2014) Inflammatory Responses Following Intramuscular and Subcutaneous Immunization with Aluminum-Adjuvanted or Non-Adjuvanted Vaccines. Vaccine, 32, 3393-3401.

https://doi.org/10.1016/j.vaccine.2014.04.018

[10] Herskind, A., Ritterband-Rosenbaum, A., Willerslev-Olsen, M., Lorentzen, J., Hanson, L., Lichtwark, G. and Nielsen, J.B. (2016) Muscle Growth Is Reduced in 15-Month-Old Children with Cerebral Palsy. Developmental Medicine \& Child Neurology, 58, 485-491. https://doi.org/10.1111/dmcn.12950

[11] Willerslev-Olsen, M., Choe-Lund, M., Lorentzen, J., Barber, L., Kofoed-Hansen, M. and Nielsen, J.B. (2018) Impaired Muscle Growth Precedes Development of Increased Stiffness of the Triceps Surae Musculotendinous Unit in Children with Cerebral Palsy. Developmental Medicine \& Child Neurology, 60, 672-679.

https://doi.org/10.1111/dmcn.13729

[12] Verschuren, O., Smorenburg, A.R.P., Luiking, Y., Bell, K., Barber, L. and Peterson, M.D. (2018) Determinants of Muscle Preservation in Individuals with Cerebral Palsy across the Lifespan: A Narrative Review of the Literature. Journal of Cachexia, Sarcopenia and Muscle, 9, 453-464. https://doi.org/10.1002/jcsm.12287

[13] Uebel, K., Pusch, K., Gedrich, K., Schneider, K.T., Hauner, H. and Bader, B.L. (2014) Effect of Maternal Obesity with and without Gestational Diabetes on Offspring Subcutaneous and Preperitoneal Adipose Tissue Development from Birth up to Year-1. BMC Pregnancy and Childbirth, 14, 138. https://doi.org/10.1186/1471-2393-14-138

[14] Durmuş, B., Ay, L., Duijts, L., Moll, H.A., Hokken-Koelega, A.C., Raat, H., Hofman, A., Steegers, E.A. and Jaddoe, V.W. (2012) Infant Diet and Subcutaneous Fat Mass in early Childhood: The Generation R Study. European Journal of Clinical Nutrition, 66, 253-260. https://doi.org/10.1038/ejcn.2011.174

[15] Durmuş, B., Ay, L., Hokken-Koelega, A.C., Raat, H., Hofman, A., Steegers, E.A. and Jaddoe, V.W. (2011) Maternal Smoking during Pregnancy and Subcutaneous Fat Mass in Early Childhood. The Generation R Study. European Journal of Epidemiology, 26, 295-304. https://doi.org/10.1007/s10654-010-9544-3 